\title{
Circadian rhythms determined by cosine curve fitting: Analysis of continuous work and sleep-loss data
}

\author{
PAUL NAITOH, CARL E. ENGLUND, and DAVID H. RYMAN \\ Naval Health Research Center, San Diego, California
}

\begin{abstract}
In this study, we report the effects of sleep loss upon circadian rhythm parameters analyzed by the cosine curve fitting (cosinor) method. Rhythm alterations are described as reductions in rhythm strength, increases in individual variations producing an increase in the $95 \%$ confidence limits, and reductions in rhythm amplitude. Subjects worked continuously at tasks for $45 \mathrm{~h}$ with time-of-day cues. Circadian cycles in physiological and mood variables remained intact, but rhythms in some task performance measures no longer showed significant 24-h/cycle activities. The relationship between oral temperature, mood, and pulse rhythms continued undisturbed during the continuous work period; however, the performance linkage to oral temperature was lost. These findings direct attention to individual difference in susceptibility to continuous work periods and suggest that 24-h rhythms in some performance and physiological measures perhaps are more readily responsive to an altered wake/sleep cycle than other circadian rhythms.
\end{abstract}

Humans are temporally organized by internal oscillatory processes to live in harmony with the environment. These internal temporal systems are coordinated with environmental events, such as the light-dark cycle, and appear to facilitate organismic survival. Being in temporal harmony with one's environment is perhaps a major criterion for health, well-being, performance effectiveness, and longevity. Research has shown that the biological bases of such organization are located in the brain and develop over time through maturation and experience. These time-keeping processes have been modeled as a set of endogenous oscillators with varying periodicities and sensitivities to environmental synchronizers (Monk et al., 1985).

Both psychological and physiological variables show the influence of endogenous oscillators by exhibiting predictable, rhythmic fluctuations over the 24-h day. Because these rhythms have been described with a recognizable frequency, usually one cycle in $24 \pm 4 \mathrm{~h}$, they are classified as circadian rhythms.

A criterion that an observed rhythm belongs to a truly endogenous circadian activity is that it continues as a rhythm for two or more cycles after prolonged sleep loss and elimination of any environmental cues or synchronizers (Halberg et al., 1971). Some biochemical, physiological, and psychological variables show persistent rhythms after disturbed sleep or short sleep deprivation (Aschoff, Fatranska, Gerecke, \& Giedke, 1974; Aschoff, Giedke, Poppel, \& Wever, 1972; Froberg, Karlsson, Levi, \& Lidberg, 1972; Murray, Williams, \&

This research was supported by the Naval Medical Research and Development Command under work unit MF58.528.01B-0003. Reprint requests should be sent to Paul Naitoh, Naval Health Research Center, Box 85122, San Diego, CA 92138-9174.
Lubin, 1958; Wever, 1970), or sleep loss up to $72 \mathrm{~h}$ (Froberg, 1977). Some other variables may show rhythmic activities, if observed under a normal 8-h sleep/16-h work routine, but the rhythmicities may disappear after removal of synchronizing events (e.g., regular sleep period) because their rhythmicities are influenced by the externally imposed rhythm of sleeping and waking. Thus, sleep loss can be used to test whether or not a given rhythmic event reflects the influences of external factors. Minors and Waterhouse (1981) stated that, if a performance task is simply affected by external factors, we easily can manipulate the phase or the period of the rhythm by changing the phase or the period of the external periodic influence. However, if a rhythm arises from within the body, it cannot easily be changed since the internal clock must be influenced. Thus, a sleep-loss study provides an important clue to the pragmatic question of whether we can expect rapid or slow changes in a performance rhythm, for example, after travel across many time zones.

In this paper, we report the effects of a $45-h$ sustained operation (SUSOP; i.e., continuous work without sleep) upon circadian rhythm parameters of physiological, performance, and mood/fatigue/sleepiness variables. We also describe the cosine curve fitting (cosinor) analysis (described in the "Analysis" section) applied to the data. [The research reported here is part of a series of SUSOPS studies at the Naval Health Research Center (NHRC), San Diego, CA (see Englund, Ryman, Naitoh, \& Hodgdon, 1985).]

\section{COSINOR ANALYSIS}

The examination of dynamic life processes requires repeated sampling as a function of time. The repeated, 
planned measurements of an event over time create a time series, which has been defined as "a set of ordered observations on a quantitative characteristic of an individual or collective phenomenon taken at different points in time" (Kendall \& Buckland, 1971, p. 153).

Most mathematical analyses of a time series require equispaced observations. This requirement can be satisfied easily by an automated-telemetered data collection system, especially when the period of the cycle or rhythm of interest is relatively short and an event is of an inanimate nature.

Due to human work-rest routines or comfort requirements, chronobiological time series are frequently not of the equispaced variety. Circumstances often force measurements when feasible, resulting in "missing data" and changes in observation time. Data are sampled at irregular intervals over an incomplete cycle or noninteger number of cycles. The resulting problems can be resolved by nonorthogonal frequency analysis (Anderson, 1971; see Naitoh, 1985; Naitoh, Lubin, \& Colquhoun, 1979).

In orthogonal frequency analysis (typical in engineering or astronomy), hidden periodicities can be searched for without a priori knowledge about the cyclic nature of the data. Nonorthogonal frequency analysis is not suitable for blind periodicity searches across a wide frequency range, because frequency resolutions can be made arbitrarily small or large by whim of an analyst. Thus, the proper use of nonorthogonal frequency analysis involves hypothesis testing and requires prior information about the frequency characteristics of the data.

Nonorthogonal frequency analysis can be regarded as an application of univariate multiple regression to a time series (Bliss, 1970; Nute \& Naitoh, 1971). Variations or rhythms in the data sample are described by using two predictors of sine and cosine waves of the same frequency. The analytic task is to measure the similarity between the observed time series and a best fitting trigonometric function (Anderson, 1971).

Univariate multiple regression equations can be computed from either a correlation matrix or from the variance-covariance matrix among the data and predictors. In this paper, we describe a computerized nonorthogonal frequency analysis based on a correlation matrix where we look for one frequency in a simple sample. The method described is the simplest of many techniques available for analysis of time-series data. When there is a data set containing many data points over a much longer period of observation, more sophisticated analytic methods than the cosine curve fitting shown in this paper should be considered (see Monk, 1982; Thorne, Genser, Sing, \& Hegge, 1983).

Refer to the data set in Table 1. We are interested in finding whether the data contains a 24-h/cycle or 1 cycle/day (cpd) activity. One cpd means that an activity makes a complete cycle of $360^{\circ}$ in $24 \mathrm{~h}$, or an angular speed of $15^{\circ} / \mathrm{h}$. Each degree represents $4 \mathrm{~min}$, because $1,440 \mathrm{~min} / 360^{\circ}=4 \mathrm{~min} / \mathrm{deg}$.

The time of observation can be expressed by an angle in terms of $1 \mathrm{cpd}$, once a beginning reference time is set.
Table 1

Example of Time Series

\begin{tabular}{cc}
\hline Data & Time of Observation \\
\hline 184 & 1900 June 1,1985 \\
178 & 2200 June 1, 1985 \\
176 & 0100 June 2, 1985 \\
172 & 0400 June 2, 1985 \\
176 & 0700 June 2, 1985 \\
182 & 1000 June 2, 1985 \\
184 & 1300 June 2, 1985 \\
180 & 1600 June 2, 1985 \\
\hline
\end{tabular}

In chronobiology, we refer to two starting times: (1) midnight and (2) midsleep (the middle of a sleep period); midnight is used as the starting time in this example. From Table 1, $1900 \mathrm{~h}$, June 1, 1985, is $5 \mathrm{~h}$ before midnight of June 1,1985 . This means that $1900 \mathrm{~h}$ is $75^{\circ}$ away from $2400 \mathrm{~h}$ in terms of $1 \mathrm{cpd}$ activity. The very same $1900 \mathrm{~h}$ of the next day, June 2,1985 , is $19 \mathrm{~h}$ past midnight of June 1 , or $285^{\circ}$ away from midnight. To distinguish time before midnight of the reference day (June 1, 1985) from after midnight, a negative sign is used for time before midnight $\left(-75^{\circ}\right.$ for $1900 \mathrm{~h}$ of June 1 ), and no sign is used for time after midnight $\left(285^{\circ}\right)$ for $1900 \mathrm{~h}$ of June 2.

Assume pure sine and cosine waves of amplitude unity (1.0) with a period of $1 \mathrm{cpd}$, starting at midnight of June 1,1985 , and extending oscillation at $1 \mathrm{cpd}$ into the past (May 31, May 30, etc.), and also into the future (June 3, June 4, etc). If the amplitude of the sine and cosine waves is measured at the same time as each data point in Table 1, we have the angle representing the data times and the corresponding sine and cosine values of that angle (see Table 2). For instance, at $1900 \mathrm{~h}$ of June 1, the value of that sine (or cosine) wave will be $\sin \left(-75^{\circ}\right)=$ -0.966 and $\cos \left(-75^{\circ}\right)=0.259$. A correlation now can be computed between the data and the sine value, and between the data and cosine value. If the data show a strong 1-cpd activity starting at midnight, then a high correlation between the data and sine or cosine value is expected.

One difficulty in using a correlation between the data and a sine or cosine wave is that the data will probably not start at $0^{\circ}$ (or have a maximal or minimal value) at midnight, which is assumed when generating the sine and cosine values in Table 2. A low correlation between the data and a sine or cosine wave does not mean that the data are not rhythmic, oscillating at $1 \mathrm{cpd}$. It may mean

Table 2

Data and 1-cpd Sine and Cosine Value

\begin{tabular}{cccrrr}
\hline Data* & Time & Day $\dagger$ & \multicolumn{1}{c}{ Angle } & \multicolumn{1}{c}{ Sine $\ddagger$} & \multicolumn{1}{c}{ Cosine } \\
\hline 184 & 1900 & 0 & -75.0 & -0.96593 & 0.25882 \\
178 & 2200 & 0 & -30.0 & -0.50000 & 0.86603 \\
176 & 0100 & 1 & 15.0 & 0.25882 & 0.96593 \\
172 & 0400 & 1 & 60.0 & 0.86603 & 0.50000 \\
176 & 0700 & 1 & 105.0 & 0.96593 & -0.25882 \\
182 & 1000 & 1 & 150.0 & 0.50000 & -0.86603 \\
184 & 1300 & 1 & 195.0 & -0.25882 & -0.96593 \\
180 & 1600 & 1 & 240.0 & -0.86603 & -0.50000 \\
\hline
\end{tabular}

*Average data point $=179 . S D=4.2762 . \quad$ to day $=$ "Today" $=$ June l. $1985 . \quad \ddagger S D=0.7559 . \quad \S S D=0.7559$. 
that the starting phase of the data is not exactly the same as that of the sine or cosine wave. To obtain the best possible correlation between the data and a sine or cosine wave, we must generate a cosinusoidal wave with a starting phase best matched with that of the data.

A cosinusoidal wave can be written (see Bliss, 1970; Monk \& Fort, 1983):

$$
\mathrm{Y}\left(\mathbf{t}_{\mathrm{i}}\right)=\operatorname{Cos}\left(\mathbf{w} \mathrm{t}_{\mathrm{i}}+\theta\right),
$$

where $Y\left(t_{i}\right)$ is the value of cosinusoidal wave at time $i$; $\mathrm{w}$ is angular velocity (e.g., $15^{\circ} / \mathrm{h}$ for $1 \mathrm{cpd}$; and $\theta$ is a phase angle. The purpose is to find a cosinusoidal wave with a phase angle that correlates highest with the data. From the trigonometric identity:

$$
\operatorname{Cos}\left(w t_{i}-\theta\right)=\operatorname{Cos} \theta \operatorname{Cos}\left(w t_{i}\right)+\operatorname{Sin} \theta \operatorname{Sin}\left(w t_{i}\right) .
$$

Setting $\operatorname{Cos} \theta=b_{c}$ and $\operatorname{Sin} \theta=b_{s}$, then Equation 2 becomes

$$
\operatorname{Cos}\left(w t_{i}-\theta\right)=b_{c} \operatorname{Cos}\left(w t_{i}\right)+b_{s} \operatorname{Sin}\left(w t_{i}\right),
$$

where $b_{c}$ is a "weight" to be multiplied to the cosine value, and $b_{s}$ is a "weight" to be multiplied to the sine value.

A cosinusoidal wave can be obtained by multiplying the cosine and sine functions (shown in Equation 3) by weighting coefficients, and adding the resultant products. The next step is to determine these two weighting coefficients. Our original problem was to determine the best fitting cosinusoidal to the data. That problem was resolved by combining Equations 1 and 3 as follows: $Y\left(t_{i}\right)=$ $b_{c} \operatorname{Cos}\left(t_{i}\right)+b_{s} \operatorname{Sin}\left(t_{i}\right)$. Determining the weighting coefficients is accomplished in the same manner as univariate multiple regression where each predictor is weighted to achieve a maximal correlation between predicted and observed values. The weights $b_{c}$ and $b_{s}$ are regression weights for the cosine and sine. We can estimate these weights by means of the multiple regression model (see Draper \& Smith, 1966).

The first step is to develop a correlation matrix (C) from the data and the predictors in Table 2, where $r_{c s}$ represents the Pearson product moment correlation between cosine and sine, and $\mathbf{r}_{c c}$ is the Pearson product moment correlation of cosine values with themselves. The $r_{c s}$ is equal to $r_{s c}$. The $r_{c d}$ and $r_{s d}$ are the Pearson product moment correlations between the cosine and data, and sine and data respectively. The $r_{d d}$ is the Pearson product moment correlation between the data with data themselves.

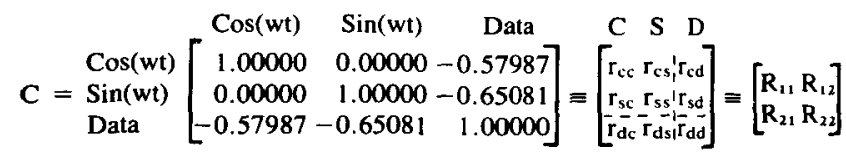

Note that $R_{11}$ in our example has a very simple structure. This is because the example (see Table 1) represents a case in which data have been collected at equidistant intervals every $3 \mathrm{~h}$ over one complete $24-\mathrm{h}$ cycle. These conditions make the predictors orthogonal to each other, resulting in a diagonal unit matrix of:

$$
\left.R_{11}=\begin{array}{ccc}
\operatorname{Cos}(w t) & \operatorname{Cos}(w t) & \operatorname{Sin}(w t) \\
\operatorname{Sin}(w t) & {\left[\begin{array}{ll}
1.00000 & 0.00000 \\
0.00000 & 1.00000
\end{array}\right]}
\end{array}\right]
$$

For nonorthogonal cases, we have nonzero correlations between the predictors:

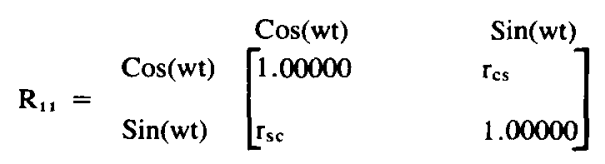

In the orthogonal cases, $R_{11}$ is inverted to become

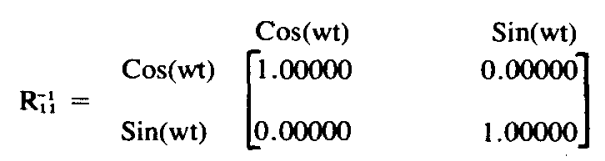

For nonorthogonal cases, an inverse $R_{11}$ can be expressed by using the identity of $r_{s c}=r_{c s}$

$$
R_{11}^{-1}=\operatorname{Cos}(w t)\left[\begin{array}{ll}
\operatorname{Cos}(w t) & \operatorname{Sin}(w t) \\
\frac{1.00000}{1-r_{s c}^{2}} & \frac{-r_{c s}}{1-r_{s c}^{2}} \\
\frac{-r_{s c}}{1-r_{s c}^{2}} & \frac{1.00000}{1-r_{s c}^{2}}
\end{array}\right]
$$

The next step is to find the standardized regression weights $B$ by solving for $B=\mathbf{R}_{11}^{-1} * \mathbf{R}_{12}$. In our example, it is

$$
B=\left[\begin{array}{ll}
1.00000 & 0.000000 \\
0.00000 & 1.000000
\end{array}\right]\left[\begin{array}{c}
-0.57989 \\
-0.65081
\end{array}\right]=\left[\begin{array}{l}
-0.57987 \\
-0.65081
\end{array}\right]
$$

In terms of nonorthogonal cases, $\mathrm{B}$ becomes

$$
B=R_{11}^{-1} *\left[\begin{array}{l}
r_{c d} \\
r_{s d}
\end{array}\right]=\left[\begin{array}{c}
\frac{r_{c d}-r_{s d} r_{s c}}{1-r_{s c}^{2}} \\
\frac{r_{c s} r_{c d}+r_{s d}}{1-r_{s c}^{2}}
\end{array}\right]
$$

The squared multiple correlation can now be computed by $R^{2}=B^{\prime} R_{12}$, which is

$$
R^{2}=(-0.57987-0.65081)\left[\begin{array}{c}
-0.57987 \\
-0.65081
\end{array}\right]=0.75980 .
$$

For nonorthogonal cases, we have (after multiplication)

$$
R^{2}=\left(r_{c d}^{2}+r_{s d}^{2}-2 r_{c d} r_{s d} r_{s c}\right) /\left(1-r_{s c}^{2}\right)
$$

Raw regression weights now can be computed by multiplying the standardized regression weight, $\mathrm{B}$, by a ratio 
of (standard deviation of data)/(standard deviation of predictor). Table 2 shows that standards deviations (SDs) of data, sine predictor, and cosine predictor are 4.2762 , 0.7559 , and 0.7559 . Hence, the raw regression weights are:

$$
\begin{gathered}
b_{c}=-0.57987(4.2762 / 0.7559)=-3.28024, \text { and } \\
b_{s}=-0.68081(4.2762 / 0.7559)=-3.68155
\end{gathered}
$$

The intercept of regression can be computed by:

$$
\begin{aligned}
& \mathbf{M}=\text { Average }_{\text {data }}-b_{c} \text { Average }_{\cos }-b_{s} \text { Average }_{\sin } \\
& \begin{array}{lll}
=179.0 & -0 & -0
\end{array} \\
& =179.0 \text {. }
\end{aligned}
$$

The average deviance is a sum of squared differences from the mean, averaged by dividing it by the number of observations; that is, $\left[(184-179)^{2}+(178-179)^{2}+\right.$ $\left.-\ldots+(180-179)^{2}\right] / 8=16.00$.

These computations have established that the observed data in Table 1 can be best described, in the least square sense, by the trigonometric function:

$$
Y\left(t_{i}\right)=179.0-3.28024 \operatorname{Cos}\left(w t_{i}\right)-3.68155 \operatorname{Sin}\left(w t_{i}\right) .
$$

Equations 1, 2, and 3 show a cosinusoid phase adjusted for maximal correlation with the data in Table 1. Recall that -3.28024 represents $\operatorname{Cos} \theta$, and -3.68155 represents $\operatorname{Sin} \theta$ in Equation 2. Amplitude (from the peak to the middle of the wave) of this raw cosinusoidal wave can be shown to be the positive square root of $\left(b_{c}\right)^{2}+\left(b_{s}\right)^{2}$, which is the positive square root of $(-3.28024)^{2}+(-3.68155)^{2}$ $=24.31378$, or 4.93 , which is the amplitude of this cosinusoidal wave.

By a trigonometric rule, the phase angle of this cosinusoidal wave can be found by taking the arctangent of the ratio of Sin weight/Cos weight, which is:

$$
\theta=\operatorname{Arctan} \frac{\text { Sin regression weight }}{\text { Cos regression weight }}=48.30^{\circ} .
$$

Since this angle falls into a quadrant where both sine and cosine are negative, the computed phase angle must be adjusted by $-180^{\circ}$ to yield the phase angle of $-228.30^{\circ}$, using the reference axis of midnight as $0^{\circ}$ (regarding angle adjustment, see Bliss, 1970; Koukkari, Duke, Halberg, \& Lee, 1974). This adjustment corresponds to $1513 \mathrm{~h}$ (3:13 p.m.). In other words, the cosinusoidal wave would show the highest or peak value at $1513 \mathrm{~h}$.

The cosinusoidal wave that we are looking for is as follows, where $\hat{Y}\left(t_{i}\right)$ is the 1-cpd component estimated to be in the data:

$$
\hat{\mathbf{Y}}\left(\mathrm{t}_{i}\right)=179.00+4.93 \operatorname{Cos}\left(w t_{i}-228.30^{\circ}\right) .
$$

Table 3 shows the comparison between the observed and estimated value $(\hat{Y})$.

According to a trigonometric identity, the variance of a cosinusoidal wave of amplitude A (one half of the dis-
Table 3

Performance of Multiple Regression Equation (1 cpd)

\begin{tabular}{cc}
\hline Data $\left[\mathrm{Y}\left(\mathrm{t}_{\mathrm{i}}\right)\right]$ & Estimated $\left[\hat{\mathrm{Y}}\left(\mathrm{t}_{\mathrm{i}}\right)\right]$ \\
\hline 184 & 182 \\
178 & 178 \\
176 & 175 \\
172 & 174 \\
176 & 176 \\
182 & 180 \\
184 & 183 \\
180 & 184 \\
\hline
\end{tabular}

tance between the peak and trough of the wave) can be represented by $\mathrm{A}^{2} / 2$, which is 12.1569 in our example.

The product moment correlation of the data and $\hat{Y}$ values in Table 3 are equal to the squared multiple correlation of 0.75980 in our example. Thus, the cosinusoidal wave of Equation 5 can explain $75.98 \%$ of the total variance in the data. The ratio of the variance of the best fitting cosinusoid of Equation 5 over the total variance of data also should be 0.7598 , and in fact (variance of the selected cosinusoidal wave)/(average deviance) $=$ $12.1569 / 16.0000=0.7598$.

How can we determine if an observed multiple correlation of 0.872 is significantly greater than zero? If it is assumed that each observation in Table 1 is independently obtained, then an $F$ ratio can be computed:

$$
F \text { ratio }\left(\mathrm{df}_{\mathrm{reg}} / \mathrm{df} f_{\text {rem }}\right)=\left(\mathrm{R}^{2} / \mathrm{df}_{\mathrm{reg}}\right) /\left(1-R^{2} / \mathrm{df} f_{\text {rem }}\right) \text {, }
$$

where $\mathrm{df}_{\text {reg }}=$ the number of predictors (in our example, 2); $\mathrm{df}_{\mathrm{rem}}=\mathrm{N}-\mathrm{K}-1$, where $\mathrm{N}$ is the number of "independent " observations and $\mathrm{K}$ is the number of predictors (in our example, 5). $\mathrm{F}$ ratio $=7.908$. Then the $\mathrm{F}$ table with dfs of 2 and 5 indicates that $F=7.908, p<.05$.

To summarize, a cosinor method can be regarded as the multiple regression analysis of fitting a cosinusoidal wave to the data. Our fictitious data had $\hat{Y}\left(t_{i}\right)=179.00$ $+4.93 \operatorname{Cos}\left(w t_{i}-228.30^{\circ}\right)$. Cosinor analysis extracts from the data, the amplitude (4.93), phase angle $\left(-228.30^{\circ}\right)$, and rhythm adjusted mean $(179.00$, called a mesor). Cosinor analysis also yields the percent variance in the data which is explained by the cosinusoidal wave $(75.98 \%$ in our example, and also referred to as r-squared, or rhythm strength). Finally, observed multiple correlation can be statistically tested to see whether it is different from zero. Usually, each time series is characterized by frequency, amplitude, and phase angle.

The cosinor analysis, as developed by Halberg (see Bingham, Arbogast, Cornelissen-Guillaume, Lee, \& Halberg, 1982), goes further in systematic analyses of the sets of many amplitude and phase angle estimates. For the details of this second-order analysis, refer to Batschelet (1981), Bethea (1975), and Englund (1979). For the exact definition of chronobiological terms, see Halberg, Carandente, Cornelissen, and Katinas (1977).

(The program for cosine curve fitting has been written for a DEC VAX/VMR system in FORTRAN. A listing 
of the program is available free of charge from the senior author, Paul Naitoh.)

\section{COSINOR METHODS APPLIED TO CONTINUOUS WORK AND SLEEP-LOSS DATA}

\section{Subjects}

Volunteer naval recruits from the United States Naval Training Center, San Diego, California, were studied in pairs, over a 5-day period. Of the 26 subjects, 3 dropped out, 1 due to an illness and 2 due to excessive fatigue and negative behavioral reactions to the SUSOP regimen. The data presented here are from 23 subjects (in groups of 15 and 8 ) who were young, healthy, and presumably fit males (ages 18-30, mean age 20.1 years).

The nature of the study and the risks involved were explained to each subject prior to our obtaining their voluntary consent to participate. All subjects could withdraw at any time or could be withdrawn by attending medical officers or experimenters.

\section{Materials}

The study was conducted in a laboratory that consisted of a sound-reduced, electronically shielded, two-bed sleep room, and a subject performance test room. Equipment included a polygraph, an FM instrumentation tape recorder, four electronic filters, four differential amplifiers, and a computer.

\section{Measurements}

Measures were taken of oral temperature in degrees Fahrenheit (F), systolic and diastolic blood pressures in $\mathrm{mmHg}$, pulse in beats per minute; of responses to the Naval Health Research Center (NHRC) Mood Scale, the Stanford Sleepiness Scale (SSS), and the School of Aerospace Medicine (SAM) Subjective Fatigue Checklist; and of performance scores on the Two-Response Alternation Performance Test (TRAP), Memory and Search Task (MAST), and the Four-Choice Serial Reaction Time Task.

The positive score on the NHRC Mood Scale (Moses, Lubin, Naitoh, \& Johnson, 1974) is the sum of the response weights assigned to each of 19 positive adjectives (such as active, alert, carefree); the score generally decreases with sleep loss. The negative score consists of the sum of the response weights to 10 negative adjectives (such as defiant, drowsy), and it increases with sleep loss.

The SSS (Hoddes, Zarcone, Smyth, Phyllips, \& Dement, 1973) medsures sleepiness on a 7-point scale, from "feeling active and vital, alert, wide awake" (1 point) to "almost in reverie, sleep onset soon, losing struggle to remain awake" (7 points).

The SAM Subjective Fatigue Checklist (Pearson \& Bayars, 1956) has been used to measure fatigue among air crews. The score of the SAM Subjective Fatigue Checklist is the sum of the weights given to each of 10 statements, such as "extremely tired," which each subject may choose one of three categories to describe his feeling state. The total score ranges from 0 to 20 points, where the lower score indicates reports of greater fatigue.

The Two-Response Alternation Performance Test (TRAP) was used as a simple psychomotor task (Friedmann et al., 1977), subjects alternately tapped two response keys, placed $4 \mathrm{~cm}$ apart for $6 \mathrm{~min}$, with eyes closed, and wearing a headphone. The subjects were instructed to tap these keys at a steady and comfortable pace. If the subject failed to press the response buttons or pressed the same response button twice, or held down both the response buttons within $2.5 \mathrm{sec}$, an alerting noise was sounded through a headphone until the proper response was made. The device generated 1-msec pulses continuously, and proper response button presses stopped generation of these pulses. These pulses and responses were recorded on cassette tapes. A computer detected and measured the interresponse intervals (IRI) in 10s of milliseconds. The cassette-recorded IRIs were analyzed to obtain two measures of TRAP: (1) the total number of responses (TRAP 1 measure), and (2) the average $10 \%$ of the slowest IRIs during the last 1-min duration of the 6-min task (TRAP 2 measure).

In the Memory and Search Task (MAST) (Monk, Knauth, Folkard, \& Rutenfranz, 1978), the subject searched through lines of 20 letters, printed out on a sheet of paper, to find the lines containing letters of a specified target. The target letters $(2,4$, or 6 letters in length) are listed at the top of each test sheet, and the subject is asked to place a check mark along the line containing the target letter, and an X mark for the remainder. Memory load was defined by the number of letters in the target. The task lasted 2 min. The MAST task was scored for total number of lines scanned in $2 \mathrm{~min}$, which included both correctly and incorrectly evaluated lines. Only the results of the MAST with 2-letter targets (2 MAST) are reported here, because the 4- and 6-letter tasks yielded qualitatively similar results.

The Wilkinson and Houghton (1975) Four-Choice Serial Reaction Time Task required subjects to press one of four buttons arranged at the corners of a square, corresponding to a similarly arranged light array directly above the response keys. One light, illuminated at random, remained on until any button was pressed; then it extinguished immediately, and another light was randomly illuminated $120 \mathrm{msec}$ following a button press. Subjects were instructed to press the buttons corresponding to the illuminated light array as quickly and as accurately as possible. The four-choice task was mechanized and housed in a modified portable cassette recorder with responses recorded on a cassette tape. Task duration was $6 \mathrm{~min}$. The computer analyzed a minute-by-minute tally of total number of responses, IRIs, and errors. The total number of responses during the first 5-min period of the task and the slowest $10 \%$ IRIs during the last minute of the 6-min task were analyzed.

[For further details of the performance assessment battery (PAB), the reader is referred to Naitoh (1981); 
Naitoh, Englund, \& Ryman (1982, 1983); and Ryman,

Naitoh, \& Englund (1984).]

\section{Procedure}

The protocol for the group of 15 subjects is shown in Figure 1. The group of 8 additional subjects experienced the same protocol except for the 2-h sleep period from 0400-0600 h. These 8 subjects remained awake during that period of time. During Sunday and Monday, all sub- jects were trained to self-measure oral temperature, pulse rate, and some performance measures, and to complete the adjective checklists. During these 2 days, subjects received extensive training on the $\mathrm{PAB}$ until reaching asymptotic levels of task performances. Monday and Tuesday were considered baseline data-collection days.

Three kinds of task sessions were used: biosessions, chore sessions, and watch sessions. Different combinations of tasks and/or measures were administered during

\begin{tabular}{|c|c|c|c|c|c|c|}
\hline & SUNDAY & $\begin{array}{l}\text { BASELINE } \\
\text { MONDAY }\end{array}$ & $\begin{array}{l}\text { BASELINE } \\
\text { TUESDAY } \\
\end{array}$ & $\begin{array}{c}\text { SUSTAINED WORK } \\
\text { WEDNESDAY }\end{array}$ & $\begin{array}{c}\text { SUSTAINED WORK } \\
\text { THURSDAY }\end{array}$ & $\begin{array}{c}\text { RECOVERY } \\
\text { FRIDAY } \\
\end{array}$ \\
\hline \multicolumn{7}{|l|}{0000} \\
\hline \multicolumn{7}{|l|}{0030} \\
\hline \multicolumn{7}{|l|}{0100} \\
\hline \multicolumn{7}{|l|}{0130} \\
\hline 0200 & & \multirow[b]{3}{*}{ SLEEP } & \multirow[b]{3}{*}{ SLEEP } & Bio-17 & Bio-29 & \multirow[b]{3}{*}{ SLEEP } \\
\hline 0230 & & & & Chore 5 & Chore 9 & \\
\hline $\begin{array}{l}0300 \\
0330\end{array}$ & & & & Bio-18 & Bio-30 & \\
\hline \multicolumn{7}{|l|}{0400} \\
\hline \multicolumn{7}{|l|}{0430} \\
\hline \multicolumn{7}{|l|}{$\begin{array}{l}0500 \\
05330\end{array}$} \\
\hline \multirow{2}{*}{\multicolumn{7}{|c|}{$\begin{array}{l}0530 \\
0600\end{array}$}} \\
\hline & & & & Bio-19 & Bio-31 & \\
\hline \multicolumn{7}{|l|}{0630} \\
\hline \multirow{2}{*}{\multicolumn{7}{|c|}{$\begin{array}{l}0700 \\
0730\end{array}$}} \\
\hline \multirow{2}{*}{\multicolumn{4}{|c|}{0800}} & & & \\
\hline & & & Bio-8 & Bio-20 & Bio-32 & Bio-41 \\
\hline \multicolumn{7}{|c|}{ Breakfast } \\
\hline \multirow{2}{*}{\multicolumn{7}{|c|}{$\begin{array}{l}0900 \\
0930\end{array}$}} \\
\hline \multirow{2}{*}{\multicolumn{3}{|c|}{ Orientation }} & & & & \\
\hline & & & Bio-9 & Bio-21 & Bio-33 & Bio-42 \\
\hline \multirow{2}{*}{\multicolumn{7}{|c|}{ Bio-34 }} \\
\hline \multirow{2}{*}{\multicolumn{7}{|c|}{$\begin{array}{l}1130 \\
1200\end{array}$}} \\
\hline & & & & & & \\
\hline 1200 & \multirow{3}{*}{$\begin{array}{l}\text { Subject pick-up } \\
\text { and orientation }\end{array}$} & & & & & \\
\hline $\begin{array}{l}1230 \\
1300\end{array}$ & & Lunch & Lunch & Lunch & SLEEP & Lunch \\
\hline \multicolumn{3}{|l|}{$\begin{array}{l}1300 \\
1330\end{array}$} & & & & \\
\hline 1400 & \multirow[t]{4}{*}{ Task training } & Bio-2 & Bio-11 & Bio-23 & Bio-35 & Bio-43 \\
\hline 1430 & & Chore 1 & Chore 3 & Chore 7 & Chore 11 & Chore 13 \\
\hline 1500 & & Bio-3 & Bio-12 & Bio-24 & Bio-36 & Bio-45 \\
\hline $\begin{array}{l}1530 \\
1600\end{array}$ & & & & & & \\
\hline $\begin{array}{l}1600 \\
1630\end{array}$ & & Dinner & Dinner & Dinner & Dinner & \\
\hline 1700 & & & & & & Debriefing \\
\hline 1730 & & Bio-4 & Bio-13 & Bio-25 & Bio-37 & \\
\hline 1800 & Dinner & Chore 2 & Chore 4 & Chore 8 & Chore 12 & Return to Base \\
\hline $\begin{array}{l}1830 \\
1900\end{array}$ & & Bio-5 & Bio.14 & Bio-26 & Bio-38 & \\
\hline $\begin{array}{l}1900 \\
1930\end{array}$ & Task training & & $810 \cdot 14$ & 010.20 & Dio-30 & \\
\hline 2000 & & Watch $1 \mathrm{~A}$ & Watch 3A & Watch 5A & Wotch 7A & \\
\hline 2030 & & & & & & \\
\hline 2100 & & & & & & \\
\hline 2130 & & Bio-6 & Bio-15 & Bio-27 & Bio-39 & \\
\hline 2200 & & & & & & \\
\hline 2230 & & & & & & \\
\hline 2300 & & Bio-7 & Bio-16 & Bio-28 & Bio-40 & \\
\hline 2330 & & & & & & \\
\hline
\end{tabular}

Figure 1. Experimental protocol for sustained work study. 
each of the types of sessions, thus marking the essential differences between them. Eight hours of sleep were allowed on Sunday, Monday, and Thursday nights. Two short naps were taken from $0400-0600 \mathrm{~h}$ and 1200-1400 $\mathrm{h}$ Thursday.

Continuous work started upon awakening at $0700 \mathrm{~h}$ Tuesday and continued until $0400 \mathrm{~h}$ Thursday, representing 2 days and nights of sustained work. Fifteen subjects were allowed to nap for $2 \mathrm{~h}$, and were awakened to continue work until noon. Another 2-h nap was taken by all subjects at noon prior to resuming work until $2330 \mathrm{~h}$
Thursday night. Nap effects are reported by Naitoh (1981). Bedtime was at midnight. Subjects continued working until $1600 \mathrm{~h}$ Friday after awakening at $0630 \mathrm{~h}$. For some tasks, subjects used task booklets fashioned systemically to follow the logical sequence of the experiment (Englund, 1979).

\section{ANALYSIS}

We anticipated that the subjects would show both practice and fatigue effects over task sessions. These effects
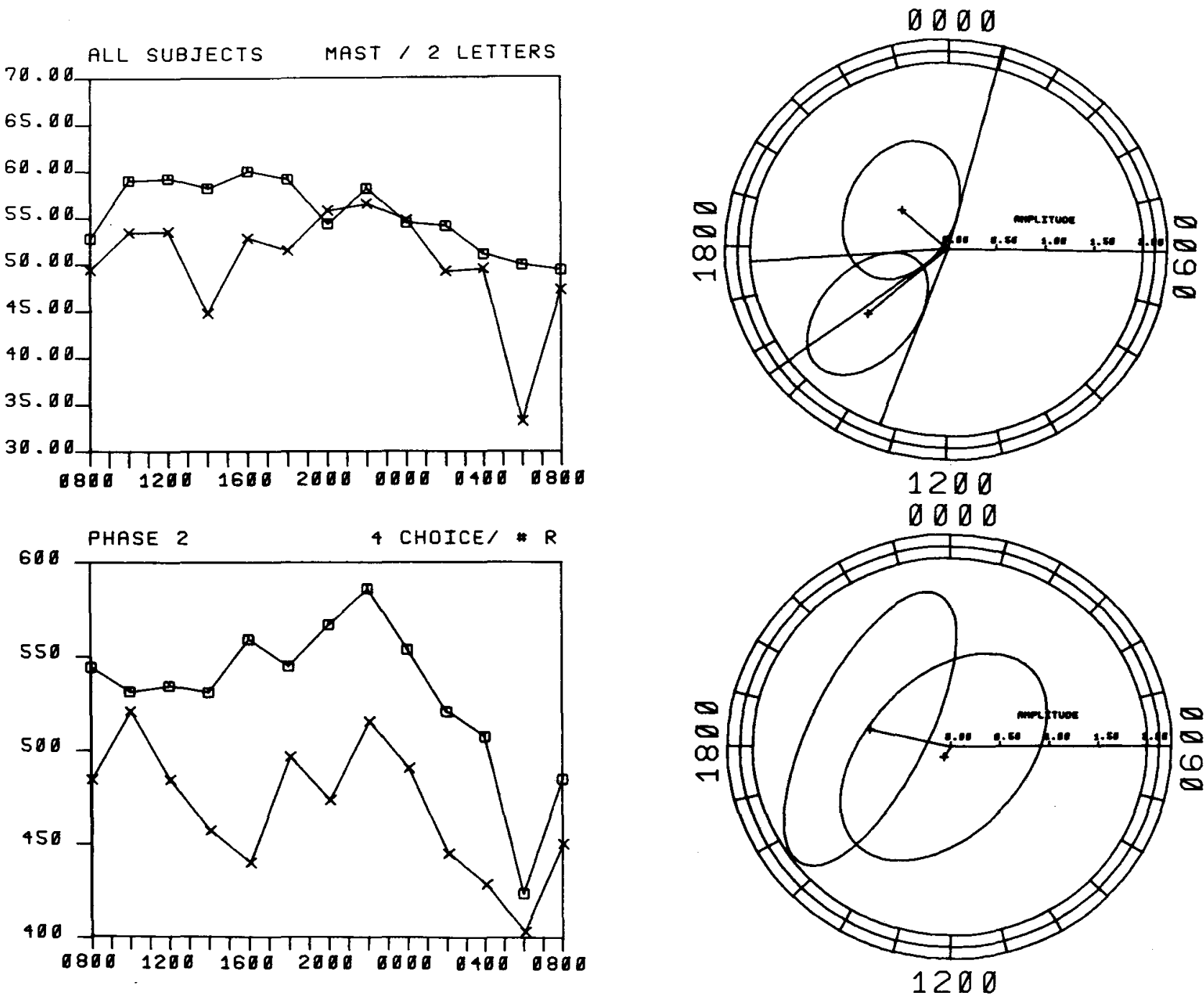

Figure 2. A chronogram (left line graphs) is a plot of averages across all subjects. The squares identify the values observed during the baseline period. The crosses identify the values during the vigil. The $X$-axis of the two chronograms is the time of day. The $Y$-axis for MAST/2 letter test is the number of lines processed by the subjects; for the Four-Choice task, it shows the total number of correct and incorrect responses. A cosinor plot (right top) shows the mean vectors and a 95\% confidence ellipse of the MAST data. The 95\% ellipse for the data from the 19 subjects during baseline are in the lower left. In the upper middle is the $95 \%$ confidence ellipse for the data during the vigil. Note that the confidence intervals are defined by tangent lines from the origin to the ellipse. The $95 \%$ confidence interval is larger for the vigil than the baseline. Another cosinor plot (right bottom) shows the mean vectors and a $95 \%$ confidence ellipse of the Four-Choice data from 8 subjects. The large confidence ellipse to the left represents a $95 \%$ confidence ellipse during baseline. During the vigil, the confidence ellipse includes the origin, suggesting that there was no statistically significant 24-h rhythmic activity common to all 8 subjects. The radius of the cosinor plot is given in an arbitrarily scaled amplitude. The " + " identifies the centroid of the vectors. 
had the potential of confounding the detection and analysis of circadian cycles in task performance. Latin square or other experimental designs generally have been used to guarantee that data at each time point in the day are represented by the performance scores of all possible test sessions (Bethea, 1975, p. 186; Blake, 1962; Monk, 1982). These designs, however, require subjects to return to the laboratory over many weeks. Because our subjects were in the laboratory only 1 week, extensive task training was given to reach asymptotic levels during the first 2 days. This procedure reduced the confounding effects of practice with circadian processes.

\section{Cosine Curve Fitting for Circadian Analysis}

First-order analysis. A 1-cpd cosine wave was fitted to the data in a manner described in the "Cosinor Analysis" section of this paper. The frequency analysis was restricted to a 24 -h period. Time-of-peak (computative acrophase) and amplitude of the 24-h/cycle activity in the data were calculated for each individual. The frequency analysis produced another index, $\mathrm{r}^{2}$ (multiple correlation squared), of the goodness-of-fit of a $24-\mathrm{h} /$ cycle sinusoidal wave to the data. This index reflected a proportion of the total variance in the raw data accounted for by the sinusoidal wave, and was expressed as percent rhythm (PR) by multiplying $\mathrm{r}^{2}$ by 100 (Halberg, Carandente, Cornelissen, \& Katinas, 1977). It is a measure of the strength of the circadian rhythm. A further analysis included determining the degree of tightness of clustering of sets of the time of peak values by use of the Rayleigh $\mathrm{Z}$ test for randomness (Batschelet, 1975).

Second-order analysis. The first-order analysis produced the estimates of rhythmicity hidden in each timeseries data, the amplitude, and phase angle. In the secondorder analysis, these individual estimates are represented as a mean vector, where length is proportional to the amplitude, and direction is determined by the phase angle. Each vector can be represented as a point on a plane. If many subjects are used and each subject yields data from at least one time series, the resulting vectors produce a scatter diagram, where each point can be regarded as a random sample from a bivariate normal distribution defined by the amplitude and phase angle. A plot of these vectors on the plane is often shown in polar coordinates as they offer a convenient way of representing each vector which consists of phase angle and amplitude. Since the distribution of vectors is bivariate normal, we can define the $95 \%$ confidence ellipse in which $95 \%$ of sampled amplitudes or phase angles are expected to fall. The right side of Figure 2 shows the $95 \%$ confidence ellipses. The left side of the figure shows chronograms of the two rhythms depicted in the cosinor plot. ${ }^{1}$

A test of significance was required to confirm that the 8-23 individual vectors were consistent in pointing to the same direction (each vector represents an individual subject in this study). A confidence region for a priori critical $F$ values was chosen to be the $95 \%$ confidence band $(p<.05)$. If the ellipse does not include the origin (coor-

Table 4

Cosinor Summary of Circadian Rhythms During Baseline (B) and Sustained Work Periods (S)

\begin{tabular}{|c|c|c|c|c|c|c|c|c|}
\hline Variable & Epoch & $\mathrm{N}$ & P R & Mesor (SD) & $\begin{array}{c}\text { Amplitude } \\
\text { Mean (95\% CI) }\end{array}$ & $\begin{array}{l}\text { Acrophase }(\mathrm{h} \mathrm{min}) \\
\text { Mean }(95 \% \mathrm{CI})\end{array}$ & $\%$ ROC & $\begin{array}{c}\text { Rayleigh } \\
\mathrm{Z} \\
\end{array}$ \\
\hline $\begin{array}{l}\text { Oral Temp } \\
\left({ }^{\circ} \mathrm{F}\right)\end{array}$ & $\begin{array}{l}\mathrm{B} \\
\mathrm{S}\end{array}$ & $\begin{array}{l}23 \\
23\end{array}$ & $\begin{array}{l}54.5 \\
53.5\end{array}$ & $\begin{array}{l}97.8(0.3) \\
97.5(0.5)\end{array}$ & $\begin{array}{l}0.5(0.4 \text { to } 0.7) \\
0.4(0.3 \text { to } 0.5)\end{array}$ & $\begin{array}{l}1722(1614 \text { to } 1819) \\
1641(1504 \text { to } 1813)\end{array}$ & $\begin{array}{l}0.6 \\
0.4\end{array}$ & $13.6 *$ \\
\hline $\begin{array}{l}\text { BP SY } \\
(\mathrm{mmHg})\end{array}$ & $\begin{array}{l}\mathbf{B} \\
\mathbf{S}\end{array}$ & $\begin{array}{l}19 \\
19\end{array}$ & $\begin{array}{l}38.3 \\
51.2\end{array}$ & $\begin{array}{l}120.3(7.5) \\
120.4(6.4)\end{array}$ & $\begin{array}{l}6.9(3.8 \text { to } 10.0) \\
9.0(5.6 \text { to } 12.4)\end{array}$ & $\begin{array}{l}1037(0856 \text { to } 1234) \\
1006(0902 \text { to } 1119)\end{array}$ & $\begin{array}{l}5.8 \\
7.5\end{array}$ & $10.7^{*}$ \\
\hline BP DI & $\begin{array}{l}\mathbf{B} \\
\mathbf{S}\end{array}$ & $\begin{array}{l}19 \\
19\end{array}$ & $\begin{array}{l}27.7 \\
29.9\end{array}$ & $\begin{array}{l}71.3(6.4) \\
70.2(6.2)\end{array}$ & $\begin{array}{l}2.7 \text { (1.0 to } 4.6) \\
\text { (no rhythm) }\end{array}$ & $\begin{array}{c}0420 \text { (0048 to } 0605) \\
\text { (no rhythm) }\end{array}$ & $\begin{array}{l}3.8 \\
-\end{array}$ & 1.4 \\
\hline $\begin{array}{l}\text { Pulse } \\
\text { (beats/min) }\end{array}$ & $\begin{array}{l}B \\
S\end{array}$ & $\begin{array}{l}19 \\
19\end{array}$ & $\begin{array}{l}31.5 \\
37.5\end{array}$ & $\begin{array}{l}63.7(5.7) \\
65.0(5.4)\end{array}$ & $\begin{array}{l}2.8(0.7 \text { to } 5.2) \\
3.3(1.3 \text { to } 5.4)\end{array}$ & $\begin{array}{l}1503(1032 \text { to } 1763) \\
1525(1306 \text { to } 1702)\end{array}$ & $\begin{array}{l}4.4 \\
5.1\end{array}$ & 2.8 \\
\hline NHRC+ & $\begin{array}{l}\mathbf{B} \\
\mathbf{S}\end{array}$ & $\begin{array}{l}22 \\
22\end{array}$ & $\begin{array}{l}48.6 \\
39.2\end{array}$ & $\begin{array}{l}3.5(2.8) \\
6.8(4.0)\end{array}$ & $\begin{array}{l}1.6(0.8 \text { to } 2.5) \\
1.6(0.8 \text { to } 2.5)\end{array}$ & $\begin{array}{l}0327(0206 \text { to } 0438) \\
0355(0154 \text { to } 0638)\end{array}$ & $\begin{array}{l}45.7 \\
23.6\end{array}$ & $6.1 \dagger$ \\
\hline SSS & $\begin{array}{l}\mathbf{B} \\
\mathbf{S}\end{array}$ & $\begin{array}{l}22 \\
22\end{array}$ & $\begin{array}{l}55.7 \\
35.7\end{array}$ & $\begin{array}{l}2.3(0.5) \\
3.3(0.8)\end{array}$ & $\begin{array}{l}0.7(0.5 \text { to } 1.0) \\
0.5(0.3 \text { to } 0.8)\end{array}$ & $\begin{array}{l}0236(0132 \text { to } 0321) \\
0339(0138 \text { to } 0538)\end{array}$ & $\begin{array}{l}31.3 \\
16.1\end{array}$ & $8.8 \dagger$ \\
\hline SAM Fatigue & $\begin{array}{l}\mathbf{B} \\
\mathbf{S}\end{array}$ & $\begin{array}{l}23 \\
23\end{array}$ & $\begin{array}{l}56.1 \\
35.3\end{array}$ & $\begin{array}{l}12.4(1.6) \\
9.8(2.6)\end{array}$ & $\begin{array}{l}2.1(1.3 \text { to } 3.0) \\
1.6(1.0 \text { to } 2.7)\end{array}$ & $\begin{array}{l}1407(1255 \text { to } 1504) \\
1511(1308 \text { to } 1728)\end{array}$ & $\begin{array}{l}17.0 \\
16.4\end{array}$ & $5.6 \dagger$ \\
\hline $\begin{array}{l}\text { TRAP 1 } \\
\text { (\# Responses) }\end{array}$ & $\begin{array}{l}\text { B } \\
\text { S }\end{array}$ & $\begin{array}{l}19 \\
19\end{array}$ & $\begin{array}{l}36.7 \\
32.6\end{array}$ & $\begin{array}{l}1033.6(237.0) \\
1006.9(247.0)\end{array}$ & $\begin{array}{l}43.8(24.3 \text { to } 66.0) \\
45.7(4.35 \text { to } 88.2)\end{array}$ & $\begin{array}{l}1946(1741 \text { to } 2234) \\
1707(1208 \text { to } 2120)\end{array}$ & $\begin{array}{l}4.3 \\
4.6\end{array}$ & 2.5 \\
\hline $\begin{array}{l}\text { TRAP } 2 \\
\text { (msec) }\end{array}$ & $\begin{array}{l}\mathbf{B} \\
\mathbf{S}\end{array}$ & $\begin{array}{l}19 \\
19\end{array}$ & $\begin{array}{l}33.2 \\
24.2\end{array}$ & $\begin{array}{l}503.9(151.9) \\
798.9(372.9)\end{array}$ & $\begin{array}{c}70.0 \text { (29.6 to } 121.3 \text { ) } \\
\text { (no rhythm) }\end{array}$ & $\begin{array}{c}0637 \text { (0410 to } 1035) \\
\text { (no rhythm) }\end{array}$ & $\begin{array}{c}13.9 \\
-\end{array}$ & 1.0 \\
\hline $\begin{array}{l}2 \text { MAST } \\
\text { (\# Lines) }\end{array}$ & $\begin{array}{l}\mathbf{B} \\
\mathbf{S}\end{array}$ & $\begin{array}{l}19 \\
19\end{array}$ & $\begin{array}{l}25.5 \\
24.1\end{array}$ & $\begin{array}{l}57.2(15.1) \\
53.1(15.0)\end{array}$ & $\begin{array}{l}4.3(1.3 \text { to } 7.3) \\
2.5(0.2 \text { to } 4.9)\end{array}$ & $\begin{array}{l}1516(1319 \text { to } 1741) \\
2045(1531 \text { to } 0058)\end{array}$ & $\begin{array}{l}7.5 \\
4.8\end{array}$ & 2.0 \\
\hline $\begin{array}{l}4 \text { Choice } \\
\text { (\# Responses) }\end{array}$ & $\begin{array}{l}\text { B } \\
S\end{array}$ & $\begin{array}{l}8 \\
8 \\
\end{array}$ & $\begin{array}{l}36.8 \\
10.2 \\
\end{array}$ & $\begin{array}{l}547.8(59.7) \\
489.5(85.5) \\
\end{array}$ & $\begin{array}{l}19.1 \text { (4.8 to } 42.2) \\
\text { (no rhythm) }\end{array}$ & $\begin{array}{c}1837 \text { (1445 to } 2353 \text { ) } \\
\text { (no rhythm) }\end{array}$ & $\begin{array}{l}3.5 \\
- \\
\end{array}$ & 1.1 \\
\hline
\end{tabular}

Note $-P R=$ percent rhythm; mesor = rhythm-determined average; amplitude $=$ measure of one-half the extent of rhythmic change in a cycle estimated by the sinusoidal function used to approximate the rhythm; acrophase mean = the average lag from a defined reference time point of the crest time in the function. BP $S Y=$ blood pressure systolic; BP DI = blood pressure diastolic. ${ }^{*} p<.01 . \quad+p<.05$. 
Table 5

Changes in Percent Rhythm $\left(\mathbf{R}^{2}\right)$ and Amplitude (A) of Circadian Rhythm

\begin{tabular}{|c|c|c|c|c|}
\hline Variable & & $\begin{array}{c}\text { Mean Difference } \\
\text { (B-S) }\end{array}$ & $\mathrm{N}$ & Exact Probability \\
\hline Oral Temp. & $\begin{array}{l}\mathrm{R}^{2} \\
\mathrm{~A}\end{array}$ & $\begin{array}{r}11.05 \\
0.10\end{array}$ & $\begin{array}{l}23 \\
23\end{array}$ & $\begin{array}{l}0.039 \\
0.083\end{array}$ \\
\hline BP SY & $\begin{array}{l}\mathrm{R}^{2} \\
\mathrm{~A}\end{array}$ & $\begin{array}{r}-12.93 \\
-1.50\end{array}$ & $\begin{array}{l}19 \\
19\end{array}$ & $\begin{array}{l}0.118 \\
0.306\end{array}$ \\
\hline NHRC+ & $\begin{array}{l}\mathrm{R}^{2} \\
\mathrm{~A}\end{array}$ & $\begin{array}{r}15.54 \\
1.18\end{array}$ & $\begin{array}{l}23 \\
23\end{array}$ & $\begin{array}{l}0.050 \\
0.128\end{array}$ \\
\hline SSS & $\begin{array}{l}R^{2} \\
A\end{array}$ & $\begin{array}{r}20.02 \\
0.08\end{array}$ & $\begin{array}{l}22 \\
22\end{array}$ & $\begin{array}{l}0.004 * \\
0.390\end{array}$ \\
\hline SAM Fatigue & $\begin{array}{l}\mathrm{R}^{2} \\
\mathrm{~A}\end{array}$ & $\begin{array}{r}20.73 \\
0.10\end{array}$ & $\begin{array}{l}23 \\
23\end{array}$ & $\begin{array}{l}0.005 * \\
0.821\end{array}$ \\
\hline TRAP 1 & $\begin{array}{l}\mathrm{R}^{2} \\
\mathrm{~A}\end{array}$ & $\begin{array}{r}4.13 \\
-33.7\end{array}$ & $\begin{array}{l}19 \\
19\end{array}$ & $\begin{array}{l}0.453 \\
0.029\end{array}$ \\
\hline 2 MAST & $\begin{array}{l}\mathrm{R}^{2} \\
\mathrm{~A}\end{array}$ & $\begin{array}{l}1.34 \\
0.15\end{array}$ & $\begin{array}{l}19 \\
19\end{array}$ & $\begin{array}{l}0.800 \\
0.900\end{array}$ \\
\hline
\end{tabular}

${ }^{*} p<.05$ two-tailed with the Dunn-Bonferroni criterion for computation of 14 tratios. Exact probability for observed difference. $B P S Y=$ blood pressure systolic.

dinates $x=0, y=0$; i.e., zero amplitude and undefined phase angle), then the center of the ellipse or the group centroid is significantly different from zero. This means that the mean vectors are significantly different from zero. Lines drawn from the origin $(0,0)$ tangent to the confidence ellipse form an angular interval which is the confidence interval (CI) for the mean acrophase (Naitoh et al., 1979; see also Nelson, Tong, Lee, \& Halberg, 1979). The significance of how tight the clustering is about a mean vector [e.g., time-of-day for highest measured value (acrophase)] can be tested by Rayleigh's Z test for randomness. This test used the phase angles of each subject and ignored the amplitudes (Batschelet, 1975, 1981).

To determine whether the sustained work period caused a shift in acrophase angles, the differences in the acrophase angles were evaluated by the Rayleigh test (Ta- ble 4). Also zero- $\mu$ t tests were used to evaluate the changes in the percent rhythm and in amplitude from the baseline value to the sustained work value (Table 5).

As a preliminary step for understanding the alteration in interrelations between variables, product-moment correlations were computed between oral temperatures and some selected variables (Table 6). Within-subject correlations were computed under the baseline condition (biosessions 8-18); then another set of within-subject correlations were computed for the sustained work condition (biosessions 20-30). Because each correlation was based on within-subject data, the test for significance could not be applied. However, if a nonzero correlation exists between two variables in a population, then the average across subjects can be nonzero, and hence can be tested for the significant difference from zero. Also, the difference between correlation coefficients observed under baseline and under sustained work conditions was calculated for each subject. The set of differences was then tested with the zero-mu t test to determine whether there was a significant change in magnitude of correlation between the baseline and the sustained work conditions. The Dunn-Bonferroni criterion (Dunn, 1959) was used to correct the level of significance (5\% two-tail).

\section{RESULTS}

Table 4 shows a summary of the cosinor analysis; Figure 3 is an acrophase map of those variables.

\section{Percent Rhythm (Rhythmic Strength)}

All variables exhibited statistically reliable rhythms (Table 4 and Figure 3 ) during the baseline. However, during the sustained work period, the percent rhythm in diastolic blood pressure (BP DI), TRAP 2, and Four Choice (4 Choice) was so reduced that reliable rhythms were no longer detected. This suggested that these measures were dependent on the sleep/wake cycle for their rhythmicity. The sleepiness (SSS) rhythm continued a statistically reli-

Table 6

Product Moment Correlations Between Oral Temperature and Some Selected Variables

\begin{tabular}{|c|c|c|c|c|c|c|c|c|c|c|}
\hline & SY BP & DI BP & Pulse & SSS & NHRC- & NHRC+ & TRAP 1 & TRAP 2 & $\begin{array}{l}4 \text { Choice } \\
\text { Total Res. }\end{array}$ & $\begin{array}{l}4 \text { Choice } \\
\text { Slow IRI }\end{array}$ \\
\hline \multicolumn{11}{|c|}{ Baseline } \\
\hline Mean & .067 & -.125 & $.337^{*}$ & $-.298 *$ & $.294 *$ & -.307 & $.298^{*}$ & -.239 & .162 & .001 \\
\hline $\mathrm{p}(\%)$ & 38.29 & 13.30 & .04 & .02 & .01 & .12 & .05 & .19 & 16.85 & 98.01 \\
\hline $\mathbf{N}$ & 19 & 19 & 19 & 22 & 23 & 22 & 19 & 19 & 8 & 8 \\
\hline SD & .360 & .339 & .331 & .305 & .311 & .332 & .303 & .277 & .266 & .333 \\
\hline$p(\%)$ & 68.97 & 14.73 & .02 & .06 & .06 & $.15^{\circ}$ & 3.12 & 30.39 & 83.79 & 43.32 \\
\hline $\mathbf{N}$ & 19 & 19 & 19 & 22 & 23 & 22 & 19 & 19 & 8 & 8 \\
\hline
\end{tabular}

Note-Baseline $=$ data collected from Bio 8 to Bio $18(0800-0400$ or $1-21$ h awake $)$. Sustained Work Period $=$ data collected from Bio 20 to Bio 30 (0800-0400, corresponding to 25-45 h awake). Mean = average correlation across subjects. $p(\%)=$ exact probability evaluated by zero-mu $t$ test and expressed in percent. *Significantly different from zero correlation with the Dunn-Bonferroni criterion for computation of 20 correlated $t$ ratios. 


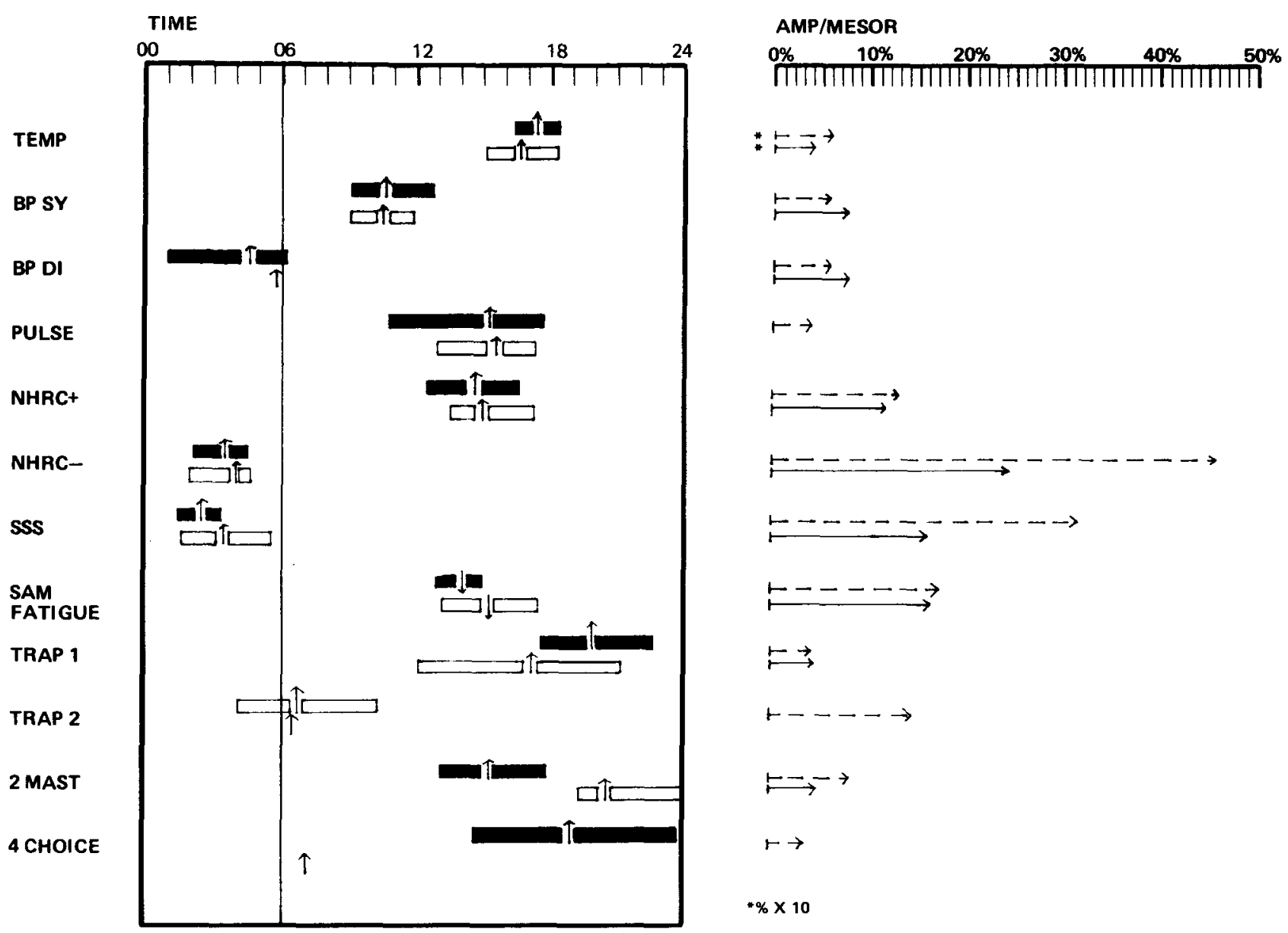

Figure 3. Acrophase map for selected variables. Acrophase and its $95 \%$ confidence intervals of 12 variables are shown on the right, together with the percent range of change $(\% R O C)$ to the left. The acrophase map shows time of day on the $X$ axis, starting from midnight to midnight of the next day. Upright arrow shows the time when a given variable shows the highest value (time of peak). Down arrow shows the time of minimal value (i.e., time of trough). Solid horizontal bars show the $95 \%$ confidence interval of acrophase angles observed during the baseline day. Unfilled horizontal bars show the same for the sustained work period (corresponding to 25-15 hours awake). When the cosinor analysis has failed to detect circadian rhythmicity, only the arrow was shown to suggest time of peak or time of trough. The \%ROC graph on the right shows the ratio of [(amplitude/mesor) $\times 100]$ seen during the baseline (broken line), and the sustained work period (solid line). Only for the case of oral temperature, the graph shows (\%ROC) $\times 10$, as \%ROC was very small for oral temperature. For the numerical details, see Table 1. BP SY = systolic blood pressure; BP DI = diastolic blood pressure. See the text for explanation of variable names.

able circadian rhythm (see Tables 4 and 5) despite a significant reduction in percent rhythm from the baseline.

\section{Amplitude}

None of circadian amplitudes, except TRAP 1, were significantly changed during the sustained work period. The increase in the amplitude of TRAP I was, however, not significant with the conservative test.

\section{5\% Confidence Ellipse}

The most dramatic change was that the $95 \%$ confidence ellipse prepared for each variable was invariably much larger during sustained work when compared with the baseline.

\section{Time of Peak (Acrophase Angle)}

Sustained work significantly shifted the time of peak
(TOP) of circadian rhythms in physiological and mood variables. None of the task performance measures showed such significant shifts in acrophase angles. For example, TOP of oral temperature was $41 \mathrm{~min}$ earlier on the average during sustained work; similarly, there was a 31 -min phase advance for TOP of systolic blood pressure, a 27 min delay for TOP of NHRC Positive Scale, a 28-min delay in TOP for NHRC Negative Scale, a 63-min delay for TOP in SSS, and a 64-min delay of TOP in SAM Subjective Fatigue Checklist. All of these changes resulted from remaining awake for up to $45 \mathrm{~h}$.

\section{Percent Range of Change}

Calculation of the percent range of change (\%ROC) shown in Table 4 and Figure 3 was based on the average mesor and average amplitude. The \% ROC was obtained by dividing the average group mesor by the average group 
amplitude and then multiplying the results by 100 . \% ROC describes the percentage of circadian modulation of each variable. For instance, oral temperature revealed a very small \% ROC (0.6) during the baseline, indicating that its amplitude would be as much as $0.3 \%$ higher or lower than the mesor, while the \%ROC for "NHRC Negative Score" would be as much as $22.9 \%$ above and $22.9 \%$ below the mesor depending on time of day. Sustained work appeared to reduce the \% ROC. Sleep loss tended to reduce the \% ROC.

\section{Relation Between Variables}

Intercorrelations between oral temperature and some selected variables are shown in Table 6. During the baseline day, oral temperature correlated significantly with pulse, SSS, NHRC - , NHRC +, TRAP 1, and TRAP 2 measures. The sustained work period did not change the intercorrelations between oral temperature, pulse, and mood measures; however, oral temperature was no longer significantly correlated with TRAP task measures.

\section{DISCUSSION}

Froberg et al. (1972) reported that body temperature, self-rated arousal, and the excretion of both adrenaline and melatonin showed persistent circadian cycles over $72 \mathrm{~h}$ of sleep loss but circadian rhythmicity in noradrenaline disappeared. Froberg also found that shooting performance showed a greater circadian activity as the hours of sleeplessness continued to $72 \mathrm{~h}$. Medd et al. (1978) observed similar persistence in circadian rhythmicity in body temperature, time estimation, short-term memory, and mood. They concluded that a $24-\mathrm{h}$ period without sleep had a minimal effect on the circadian cycle. Cutler and Cohen (1979) observed, in one night of sleep loss, that the circadian cycle in SSS and body temperature continued unchanged.

Aschoff and his associates $(1972,1974)$, and Wever (1970) reported that sleep loss of up to 2 nights did not seriously affect circadian cycles, and that interrupted sleep did not result in a significant distortion of the circadian cycle in rectal temperature. By inspecting plots of averages across time of day, they observed that sleep loss reduced the amplitude of the average plot of rectal temperature, time estimation, and tapping rate, and that the nightly circadian fall was smaller when subjects remained awake. The minimum point (time of trough) for tapping and grip strength tasks came $3 \mathrm{~h}$ earlier.

Since none of these studies examined rhythmicity in individual subjects with the cosinor method, it is difficult to determine whether a reduction in the amplitude of average rectal temperatures was caused by actual reduction in amplitude or by the increased scatter of individual TOPs (i.e., a loss of synchronization as a group). In fact, Murray et al. (1958) described an increase in the amplitude of the oral temperature rhythm during the course of $98 \mathrm{~h}$ of sleep loss.

Table 4 shows that sleeplessness of up to $45 \mathrm{~h}$ lengthened the $95 \%$ confidence intervals for acrophase angles of oral temperature. Thus, as far as oral temperature is concerned, the significant changes in circadian cycle were decreased average rhythmicity and a larger $95 \%$ confidence ellipse. A major effect, therefore, of the sustained work period on circadian cycles was to create a greater variability in TOPs among the individual subjects. The reduced group circadian amplitude seen in body temperature and other variables during the sustained work period might be explained in part by the greatly increased individual difference in acrophase. In the extreme case, a circadian rhythm was no longer detectable [i.e., diastolic blood pressure, TRAP 2 measure, and Four Choice (number of responses)].

This increase in $95 \%$ confidence intervals for acrophase angles or TOP occurred, despite clear cues available to the subjects regarding time of day. The subjects were housed in wooden barracks with many windows and subjected to sunshine and outdoor activity noises. Despite abundant time cues, some physiological and mood variable showed significant phase changes. The TRAP 1 and the two MAST performance measures did not phase advance or delay during the vigil. The results on phase angle shifts do not fully agree with those phase advances reported by Aschoff and colleagues (1972, 1974). Perhaps this difference may be due to the open environment referred to earlier.

Apparent loss of circadian rhythmicity in TRAP 2 and Four Choice might be an artifact of the analysis. Our hypothesis-testing approach did not include an examination of the rhythmic activities during other periods. The vigil simply could have shifted the period length. Also, the apparent loss could have occurred when individual subjects have TOPs, not at a narrow time range, but almost any time of day due to different sensitivities to the vigil. Further study is required to determine the causes of rhythm loss. Whatever the causes, these variables seem to maintain circadian rhythmicity only when regular sleep/wakefulness hours are kept. Thus, the rhythms are more influenced by external factors of the wake/sleep cycle than by the other variables that do maintain their circadian rhythm during sustained work. Diastolic blood pressure may be as much influenced by external factors as some behavioral performance measures.

The results of this study extend the findings of Moses, Lubin, Naitoh, and Johnson (1978) confirming the relationship between sleepiness and oral temperature during the baseline and sleep-loss period with work, although a significant correlation between oral temperature and task peformance during sustained work was not found.

\section{REFERENCES}

ANDERSON, T. W. (1971). The statistical analysis of time series. New York: Wiley.

Aschoff, J., Fatranska, M., Gerecke, U., \& Giedke, H. (1974). Twenty-four hour rhythms of rectal temperature in humans: Effects of sleep interruptions and of test sessions. Pflugers Archives, 346, 215-222.

Aschoff, J., Giedke, H., Popper, E., \& Wever, R. (1972). The influence of sleep interruption and of sleep deprivation on circadian 
rhythms in human performance. In W. P. Colquhoun (Ed.), Aspects of human efficiency (pp. 135-150). London: English University Press. BATSCHELET, E. (1975). Statistical methods for the analysis of problems in animal orientation and certain biological thythms. American Institute of Biological Science Monograph, p. 57.

BATSCHELET, E. (1981). Circular statistics in biology. New York: Academic Press.

BETHEA, N. J. J. (1975). Human performance, physiological rhythms, and circadian time relations. Dissertation Abstracts International, 36/06-B, 2637. (University Microfilms No. 75-26, 834)

Bingham, C., Arbogast, B., Cornelissen-Guillaume, G., Lee, J- K., \& HALBERG, F. (1982). Inferential statistical methods for estimating and comparing cosinor parameters. Chronobiologia, 9, $397-439$.

BlAKE, M. J. F. (1962). Time of day effects on performance in a range of tasks. Psychonomic Science, 9, 349-350.

Busss, C. I. (1970). Periodic regression. In C. I. Bliss (Ed.), Statistics in biology (Vol. 2, pp. 219-287). New York: McGraw-Hill.

Cutler, N. R., \& CoHEN, H. B. (1979). The effect of one night's sleep loss on mood and memory in normal subjects. Comprehensive Psychiatry, 20, 61-66.

DRAPER, N. R., \& SMITH, H. (1966). Applied regression analysis. New York: Wiley.

DunN, O. J. (1959). Confidence intervals for the means of dependent normally disturbed variables. Journal of American Statistical Association, 54, 613-621.

ENGLUND, C. E. (1979). Human chronopsychology: An autorhythmometric study of circadian periodicity in learning, mood and task performance. Dissertation Abstracts International, 41/03-B, 1139. (University Microfilms International No. 80-19, 029)

Englund, C. E., Ryman, D. H., Naitoh, P., \& Hodgdon, J. A. (1985). Cognitive performance during successive sustained physical work episodes. Behavior Research Methods, Instruments, \& Computers, 17. 75-85.

Friedmann, J., Globus, G. G., Huntley, A., Mullaney, D., NaItoh, P., \&ohnson, L. C. (1977). Performance and mood during and after gradual sleep reduction. Psychophysiology, 14, 245-250.

FroBerG, J. E. (1977). Twenty-four hour patterns in human performance, subjective and physiological variables and differences between morning and evening active subjects. Biological Psychology, 5. 119-134.

Froberg, J., Karlsson, C., Levi, L., \& Lidberg, L. (1972). Circadian variations in performance, psychological ratings, catecholamine excretion, and diuresis during prolonged sleep deprivation. International Journal of Psychobiology, 2, 23-36.

Halberg, F., Carandente, F., Cornelissen, G., \& Katinas, G. S. (1977). Glossary of chronobiology. Milano. Italy: International Society for Chronobiology.

Halberg, F., Nelson, W., Runge, W. J., Schmitt, O. H., Pitts, G., Tremor, J., \& Reynolds, O. E. (1971). Plans for orbital study of rat biorhythms. Results of interest beyond the Biosatellite program. Space Life Science, 2, 437-471.

Hoddes, E., Zarcone, V., Smyth, H., Phyllips, R., \& Dement, W. C. (1973). Quantification of sleepiness: A new approach. Psychophysiology, 10, 431-436.

Kendall, M. G.. \& BuCKLAND, W. R. (1971). A dictionary of statistical terms. New York: Hafner.

Koukkari, W. R.. Duke, S. H., Halberg, F., \& Lee, L. K. (1974). Circadian rhythmic leaflet movements: Student exercise in chronobiology. Chronobiologia. 1. 281-302.

Medd, A., Taggart, E.. Kuiack, J. J., Rowntree, C., Rideout. P., Hubbard, N., Pawlus, O., Prince, J., Rubenstein, D. . Lutz. R.. Galvin, G., \& OGILviE, R. (1978). Sleep deprivation and circadian mood and performance measures. Sleep Research, 7, 273.

Minors. D. S. \& W A TERHOUSE, J. M. (1981). Circadian rhythms and the human. Bristol, England: John Wright \& Sons.

Monk. T. H. (1982). Research methods of chronobiology. In W. B. Webb (Ed.), Biological rhythms, sleep and performance. New York: Wiley.

Monk, T. H., Fookson, J. E., Kream, J., Moline, M. L., Pollak, C. P., \& WeItzman, M. B. (1985). Circadian factors during sustained performance: Background and methodology. Behavior Research
Methods, Instruments, \& Computers. 17, 19-26.

Monk, T. H., \& FORT, A. (1983). 'Cosina': A cosine curve fitting program suitable for small computers. International Journal of Chronobiology, 8, 193-224.

Monk, T. H., Knauth, P., Folkard, S., \& Rutenfranz, J. (1978). Memory based performance measures in studies of shiftwork. Ergonomics, 21, 819-826.

Moses, J. M., Lubin, A., NaItoh, P., \& Johnson, L. C. (1974). Subjective evaluation of the effects of sleep loss: The NHRC mood scales (Tech. Rep. No. 74-25). San Diego: Naval Health Research Center. Moses, J., Lubin, A., NarToH, P., \& Johnson, L. C. (1978). Circadian variations in performance, subjective sleepiness, sleep and oral temperature during an altered sleep-wake schedule. Biological Psychology, 6, 301-308.

MurRay, E. J., Williams, H. L., \& Lubin, A. (1958). Body temperature and psychological ratings during sleep deprivation. Journal of Experimenal Psychology, 56, 271-273.

NaIToH, P. (1981). Circadian cycles and restorative power of naps. In L. C. Johnson, D. I. Tepas, W. P. Colquhoun, \& M. J. Colligan (Eds.), Biological rhythms, sleep and shift work (pp. 553-580). New York: Spectrum.

NaIToH, P. (in press). In search of REM cycle in short sleep record: Iterative nonorthogonal $r$-squared method. In H. Schulz \& P. Lavie (Eds.), Ultradian rhythms in physiology and behavior.

Naitoh, P., Englund, C. E., \& Ryman, D. H. (1982). Restorative power of naps in designing continuous work schedules. Journal of Human Ergology, 11(Suppl.), 259-278.

Naitoh, P., Englund, C. E., \& Ryman, D. H. (1983, May). Extending human effectiveness during sustained operations through sleep management. In Proceedings of the 24th DRG Seminar on the Human as a Limiting Element in Military Systems, 1, 113-138. Toronto, Canada: NATO Defense Research Group.

Naitoh, P., Lubin, A., \& Colquhoun, W. P. (1979). Comparisons of monosinusoidal with bisinusoidal (two wave) analysis (Tech. Rep. No. 79-29). San Diego: Naval Health Research Center.

Nelson, W., Tong, Y. L., LeE, J-K, \& HalberG, F. (1979). Methods for cosinor-rhythmometry. Chronobiologia, 4, 305-323.

Nute, C., \& NAITOH, P. (1971). A generalization of harmonic analysis for detection of long-period biorhythmicities for short records. (Tech. Rep. No. 71-55). San Diego: Navy Medical Neuropsychiatric Research Unit.

Pearson, R., \& Bayars, G. E. (1956). The development and validation of a checklist for measuring subjective fatigue (USAF Tech. Rep. 56-115). Randolph AFB, TX: School of Aerospace Medicine.

Ryman, D. H., NaIToh, P., \& Englund, C. E. (1984). Minicomputer administered tasks in the study of effects of sustained work on human performance. Behavior Research Methods, Instruments, \& Computers, 16, 256-261.

Thorne, D., Genser, S., Sing, H., \& Hegge, F. (1983). Plumbing human performance limits during 72 hours of high task load. In Proceedings of the 24th Seminar on the Human as a Limiting Element in Military Systems, 1, 17-40. Totonto, Canada: NATO Defense Research Group.

WEVER, R. (1970). Circadian rhythms of some psychologial functions under different conditions. In A. J. Benson (Ed.), AGARD Conf. Proceedings No. 44 on rest and activity cycles for the maintenance of efficiency of personnel concerned with military flight operations (pp. 1-10). Paris: NATO.

Wilkinson, R. T., \& Houghton, D. (1975). Portable four-choice reaction time test with magnetic tape memory. Behavior Research Methods \& Instrumentation. 7, 441-446.

\section{NOTE}

1. Refer to Halberg. Carandente, Cornelissen, and Katinas, 1977. A chronogram displays original or averaged data in time order of collection along any scale of one or more time units. A cosinor plot is a statistical summary (group mean-cosinor) with display on polar coordinates of a biologic rhythm's amplitude and acrophase relations by means of the length and the angle of a directed line, respectively, shown with a bivariate statistical confidence region. 